\author{
V.A. Roman'kov \\ F.M. Dostoevsky Omsk State University, Russia \\ (E-mail: romankov48@mail.ru)
}

\title{
A polynomial algorithm for the braid double shielded public key cryptosystems
}

\begin{abstract}
We propose new provable practical deterministic polynomial time algorithm of cryptographic analysis for the braid Wang, $\mathrm{Xu}, \mathrm{Li}$, Lin and Wang «Double shielded public key cryptosystems», where the authors recommended the Artin braid groups $B_{n}$ as platforms for proposed protocols. We show that a linear decomposition attack based on the decomposition method introduced by the author works for the image of braids under the Lawrence-Krammer representation by finding the exchanging keys in the both two main protocols by Wang et. al. These keys can be effectively computed in their original form too. Thus the protocols proposed by Wang et. al. are vulnerable.
\end{abstract}

Key words: cryptography, protocol, braid group, cryptanalysis, attack, linear decomposition, representation.

\section{Introduction}

In this paper we discuss, following [1, 2], a new practical attack on the two main protocols proposed in [3]. This attack works when the platform groups are linear. We show that in this case, contrary to the common opinion (and some explicitly stated security assumptions), one does not need to solve the underlying algorithmic problems to break the scheme, i.e., there is another algorithm that recovers the private keys without solving the principal algorithmic problem on which the security assumptions are based. This changes completely our understanding of security of these schemes. The efficacy of the attack depends on the platform group, so it requires a specific analysis in each particular case. In general one can only state that the attack is in polynomial time in the size of the data, when the platform and related groups are given together with their linear representations. In many other cases we can effectively use known linear representations of the groups under consideration. The braid groups are among them in view of the Lawrence-Krammer representation. The monography [1] solves uniformly protocols based on the conjugacy search problem (Ko et. al. [4], Wang et. al. [5]), protocols based on the decomposition and factorization problems (Stickel [6], Alvares et. al. [7], Shpilrain and Ushakov [8]), protocols based on actions by automorphisms (Mahalanobis [9], Habeeb, Kahrobaei et. al. [10], Markov, Mikhalev et.al. [11]), and a number of other protocols. In this paper we apply our method to the double shielded key exchange protocols 1 and 2 proposed in [3].

\section{Construction of a basis}

Let $V$ be a finite dimensional vector space over a field $F$ with basis $B=\left\{v_{1}, \ldots, v_{r}\right\}$. Let $\operatorname{End}(V)$ be the semigroup of endomorphisms of $V$. We assume that elements in $V$ are given as vectors relative to $B$, and endomorphisms in End $(V)$ are given by their matrices relative to $B$. Let $\langle W\rangle$ denotes submonoid generated by $W$.

For an endomorphism $a \in \operatorname{End}(V)$ and an element $v \in V$ we denote by $v^{a}$ the image of $v$ under $a$. Also, for any subsets $W$ of $V$ and $A$ of $\operatorname{End}(V)$ we put $W^{A}=\left\{w^{a} \mid w \in W, a \in A\right\}$, and denote by $\operatorname{Sp}(W)$ the subspace of $V$ generated by $W$. We assume that elements of the field $F$ are given in some constructive form and the «size» of the form is defined. Furthermore, we assume that the basic field operations in F are efficient, in particular they can be performed in polynomial time in the size of the elements. In all the particular protocols considered in this paper the field $F$ satisfies all these conditions.

There is an algorithm that for given finite subsets $W \subseteq V$ and $U \subseteq \operatorname{End}(V)$ finds a basis of the subspace $\operatorname{Sp}\left(W^{<U>}\right)$ in the form $\left\{w_{1}^{a(1)}, \ldots, w_{t}^{a(t)}\right\}$, where $w_{i} \in W$ and $a(i)$ is a product of elements from $U$. Furthermore, the number of field operations used by; the algorithm is polynomial in $r=\operatorname{dim}_{F}(V)$ and the cardinalities $|W|$ and $|U|$ of $W$ and $U$, respectively. 
Using Gauss elimination one can effectively find a maximal linearly independent subset $L_{0}$ of $W$. Notice that $\operatorname{Sp}\left(L_{0}^{<U>}\right)=\operatorname{Sp}\left(W^{<U>}\right)$. Adding to the set $L_{0}$ one by one elements $v^{a}$, where $v \in L_{0}$,

$a \in U$ and checking every time linear independence of the extended set, one can effectively construct a maximal linearly independent subset $L_{1}$ of $L_{0} \cup L_{0}^{U}$ which extends the set $L_{0}$. Notice that $\operatorname{Sp}\left(L_{0}^{<U>}\right)==\operatorname{Sp}\left(L_{1}^{<U>}\right)$ and the elements in $L_{1}$ are of the form $w^{a}$, where $w \in W$ and $a=1$ or $a \in U$. It follows that if $L_{0}=L_{1}$ then $L_{0}$ is a basis of $\operatorname{Sp}\left(W^{<U>}\right)$. If $L_{0} \neq L_{1}$ then we repeat the procedure for $L_{1}$ and find a maximal linearly independent subset $L_{2}$ of $L_{1} \cup L_{1}^{U}$ that extends $L_{1}$. Keep going one constructs a sequence of strictly increasing subspaces $L_{0}<L_{1}<\ldots<L_{i}$ of $V$. Since the dimension $r$ of $V$ is finite the sequence stabilizes for some $i \leq r$. In this case $L_{i}$ is a basis of $\operatorname{Sp}\left(W^{<U>}\right)$ and its elements are in the required form.

To estimate the upper bound of the number of the field operations used by the algorithm, observe first that the number of the field operations in Gauss elimination performed on a matrix of size $n \times r$ is $\mathrm{O}\left(n^{2} r\right)$. Hence it requires at most $\mathrm{O}\left(n^{2} r\right)$ steps to construct $L_{0}$ from $W$, where $n=|W|$ is the number of elements in $W$. Notice that $\left|L_{j}\right| \leq r$ for every $j$. So to find $L_{j+1}$ it suffices to perform Gauss elimination on the matrix corresponding to $L_{j} \cup L_{j}^{U}$ which has size at most $r+r|U|$. Thus the upper estimate on this number is $\mathrm{O}\left(r^{3}|U|^{2}\right)$. Since there are at most $r$ iterations of this procedure one has the total estimate as $\mathrm{O}\left(r^{3}|U|^{2}+r|W|^{2}\right)$.

In this paper $V$ is underlying linear space of a matrix algebra $\operatorname{Mat}_{t}(F)$ of all matrices of size $t \times t$ over $F$. Let $G$ be a subgroup of the multiplicative group of $\operatorname{Mat}_{t}(F)$, and $A$ and $B$ are two subgroups of $G$. Every pair of elements $a \in A$ and $b \in B$ define an automorphism $\varphi(a, b)$ of $V$ such that for every $v \in V$ one has $v^{\varphi(a, b)}=a v b$. Let $U$ be submonoid generated by all such automorphisms. Thus for every subset $W \subseteq V$ one can effectively construct a basis of subspace $W^{U}$.

\section{The double shielded key exchange protocol 1 from [3]}

At first we describe the protocol 1 from [3]. Recall that in [3] the Artin braid groups $B_{n}$ were recommended as platforms for the proposed protocols constructing.

In view of the Lawrence-Krammer representation of the braid group $B_{n}$ we can assume that the group $G$ below is given as a linear group over a field $F$. So, we assume that $G$ is a part of a finite dimensional vector space $V$.

Alice and Bob agree on a non-abelian group $G$, and randomly chosen element $h \in G$ and two subgroups $A$ and $B$ of $G$, such that $a b=b a$ for any $a \in A$ and any $b \in B$. We assume that $A$ and $B$ are finitely generated and are given by the fixed generating sets $\left\{a_{1}, \ldots, a_{n}\right\}$ and $\left\{b_{1}, \ldots, b_{m}\right\}$, respectively.

Alice chooses four elements $c_{1}, c_{2}, d_{1}, d_{2} \in A$, computes $x=d_{1} c_{1} h c_{2} d_{2}$ and then sends $x$ to Bob.

Bob chooses six elements $f_{1}, f_{2}, g_{1}, g_{2}, g_{3}, g_{4} \in B$, computes $y=g_{1} f_{1} h f_{2} g_{2}$ and $w=g_{3} f_{1} x f_{3} g_{4}$, and then sends $(y, w)$ to Alice. Bob.

Alice chooses two elements $d_{3}, d_{4} \in A$, computes $z=d_{3} c_{1} y c_{2} d_{4}$ and $u=d_{1}^{-1} w d_{2}^{-1}$, and then sends $(z, u)$ to

Bob sends $v=g_{1}^{-1} z g_{2}^{-1}$ to Alice.

Alice computes $K_{A}=d_{3}^{-1} v d_{4}^{-1}=c_{1} f_{1} h f_{2} c_{2}$.

Bob computes $K_{B}=g_{3}^{-1} u g_{4}^{-1}=c_{1} f_{1} h f_{2} c_{2}$ which is equal to $K_{A}$ and then $K=K_{A}=K_{B}$ is Alice and Bob's common secret key.

Now we show how the common secret key can be computed. Let $B z B$ be subspace of $V$ generated by all elements of the form $f z g$ where $f, g \in B$. We can construct a basis $\left\{e_{i} z l_{i}\left(e_{i}, l_{i} \in B, i=1, \ldots, r\right)\right\}$ of $B z B$ in a polynomial time as it is explained in the previous section. Since $v \in B z B$, we can effectively write it in the form

$$
v=\sum_{i=1}^{r} \alpha(i) e_{i} z l_{i}
$$

where $\alpha(i) \in F$ for $i=1, \ldots, r$. In a similar way we construct bases $\left\{e_{j}^{\prime} h l_{j}^{\prime}\left(e_{j}^{\prime}, l_{j}^{\prime} \in B, j=1, \ldots, s\right)\right\}$ of $B h B$, and $\left\{e_{k}^{\prime \prime} w l_{k}^{\prime \prime}\left(e_{k}^{\prime \prime}, l_{k}^{\prime \prime} \in B, k=1, \ldots, q\right)\right\}$ of $B w B$. Then we get presentations

$$
y=\sum_{j=1}^{s} \beta(j) e_{j}^{\prime} h l_{j}^{\prime},
$$

where $\beta(j) \in F$ for $j=1, \ldots, s$, and

$$
x=\sum_{k=1}^{q} \gamma(k) e_{k}^{\prime \prime} w l_{k}^{\prime \prime}
$$


where $\gamma(k) \in F$ for $k=1, \ldots, q$.

Now we swap $w$ by $u$ in the right hand side of (3). By direct computation we obtain

$$
\sum_{k=1}^{q} \gamma(k) e_{k}^{\prime \prime} u l_{k}^{\prime \prime}=\sum_{k=1}^{q} \gamma(k) e_{k}^{\prime \prime} d_{1}^{-1} w d_{2}^{-1} l_{k}^{\prime \prime}=d_{1}^{-1}\left(\sum_{k=1}^{q} \gamma(k) e_{k}^{\prime \prime} w l_{k}^{\prime \prime}\right) d_{2}^{-1}=d_{1}^{-1} x d_{2}^{-1}=c_{1} h c_{2} .
$$

Then we swap $h$ by $c_{1} h c_{2}$ in the right hand side of (2) and get

$$
\sum_{j=1}^{s} \beta(j) e_{j}^{\prime} c_{1} h c_{2} l_{j}^{\prime}=c_{1}\left(\sum_{j=1}^{s} \beta(j) e_{j}^{\prime} h l_{j}^{\prime}\right) c_{2}=c_{1} y c_{2}=c_{1} g_{1} f_{1} h f_{2} g_{2} c_{2} .
$$

At last we swap $z$ by $c_{1} g_{1} f_{1} h f_{2} g_{2} c_{2}$ in the right hand side of (1) and get

$$
\sum_{i=1}^{r} \alpha(i) e_{i} c_{1} g_{1} f_{1} h f_{2} g_{2} c_{2} l_{i}=d_{3}^{-1}\left(\sum_{i=1}^{r} \alpha(i) e_{i} z l_{i}\right) d_{4}^{-1}=c_{1} f_{1} h f_{2} c_{2}=K
$$

The double shielded key exchange protocol 2 from [3]

Now we describe the protocol 2 from [3].

As before we assume that the group $G$ below is given as a linear group over a field $F$. So, we assume that $G$ is a part of a finite dimensional vector space $V$.

Alice and Bob agree on a non-abelian group $G$, and randomly chosen element $h \in G$ and two subgroups $A$ and $B$ of $G$, such that $a b=b a$ for any $a \in A$ and any $b \in B$. We assume that $A$ and $B$ are finitely generated and are given by the fixed generating sets $\left\{a_{1}, \ldots, a_{n}\right\}$ and $\left\{b_{1}, \ldots, b_{m}\right\}$, respectively.

Alice chooses four elements $c_{1}, d_{1} \in A$ and $f_{2}, g_{2} \in B$, computes $x=d_{1} f_{1} h_{2} d_{2}$ and then sends $x$ to Bob.

Bob chooses six elements $c_{2}, d_{2}, d_{3} \in A$ and $f_{1}, g_{1}, g_{3} \in B$, computes $y=g_{1} f_{1} h c_{2} d_{2}$ and $w=g_{3} f_{1} x c_{2} d_{3}$, and then sends $(y, w)$ to Alice.

Alice chooses two elements $d_{4} \in A$ and $g_{4} \in B$, computes $z=d_{4} c_{1} y f_{2} g_{4}$ and $u=d_{1}^{-1} w g_{2}^{-1}$, and then sends $(z, u)$ to Bob.

Bob sends $v=g_{1}^{-1} z d_{2}^{-1}$ to Alice.

Alice computes $K_{A}=d_{4}^{-1} v g_{4}^{-1}$. Bob computes $K_{B}=g_{3}^{-1} u d_{3}^{-1}=c_{1} f_{1} h f_{2} c_{2}$ which is equal to $K_{A}$ and then $K=K_{A}=K_{B}$ is Alice and Bob's common secret key.

Now we show how the common secret key can be computed. Let $B z A$ be subspace of $V$ generated by all elements of the form $f z d$ where $f \in B, d \in A$.

We can construct a basis $\left\{e_{i} z l_{i}\left(e_{i} \in B, l_{i} \in A, i=1, \ldots, r\right)\right\}$ of $B z A$ in a polynomial time as it is explained in the previous section. Since $v \in B z A$, we can effectively write it in the form

$$
v=\sum_{i=1}^{r} \alpha(i) e_{i} z l_{i}
$$

where $\alpha(i) \in F$ for $i=1, \ldots, r$.

In a similar way we construct bases $\left\{e_{j}^{\prime} h l_{j}^{\prime}\left(e_{j}^{\prime} \in B, l_{j}^{\prime} \in A, j=1, \ldots, s\right)\right\}$ of $B h A$, and $\left\{e_{k}^{\prime \prime} w l_{k}^{\prime \prime}\left(e_{k}^{\prime \prime} \in\right.\right.$ $\left.\left.\in B, l_{k}^{\prime \prime} \in A, k=1, \ldots, q\right)\right\}$ of $B w A$.

Then we get presentations:

$$
y=\sum_{j=1}^{s} \beta(j) e_{j}^{\prime} h l_{j}^{\prime},
$$

where $\beta(j) \in F$ for $j=1, \ldots, s$, and

$$
x=\sum_{k=1}^{q} \gamma(k) e_{k}^{\prime \prime} w l_{k}^{\prime \prime},
$$

where $\gamma(k) \in F$ for $k=1, \ldots, q$. 
Now we swap $w$ by $u$ in the right hand side of (9). By direct computation we obtain

$$
\sum_{k=1}^{q} \gamma(k) e_{k}^{\prime \prime} u l_{k}^{\prime \prime}=\sum_{k=1}^{q} \gamma(k) e_{k}^{\prime \prime} d_{1}^{-1} w g_{2}^{-1} l_{k}^{\prime \prime}=d_{1}^{-1}\left(\sum_{k=1}^{q} \gamma(k) e_{k}^{\prime \prime} w l_{k}^{\prime \prime}\right) g_{2}^{-1}=d_{1}^{-1} x g_{2}^{-1}=c_{1} h f_{2}
$$

Then we swap $h$ by $c_{1} h f_{2}$ in the right hand side of (8) and get

$$
\sum_{j=1}^{s} \beta(j) e_{j}^{\prime} c_{1} h f_{2} l_{j}^{\prime}=c_{1}\left(\sum_{j=1}^{s} \beta(j) e_{j}^{\prime} h l_{j}^{\prime}\right) f_{2}=c_{1} y f_{2}=c_{1} g_{1} f_{1} h c_{2} d_{2} f_{2} .
$$

At last we swap $z$ by $c_{1} g_{1} f_{1} h c_{2} d_{2} f_{2}$ in the right hand side of (7) and get

$$
\sum_{i=1}^{r} \alpha(i) e_{i} c_{1} g_{1} f_{1} h c_{2} d_{2} f_{2} l_{i}=d_{4}^{-1}\left(\sum_{i=1}^{r} \alpha(i) e_{i} z l_{i}\right) g_{4}^{-1}=c_{1} f_{1} h c_{2} f_{2}=K
$$

Two other, the shielded public key encryption protocol and the shield digital signature protocol in [3] completely based on the protocols 1 and 2 . They can be attacked by the procedures that has been just described.

\section{The Lawrence-Krammer representation}

Let $B_{n}$ denotes the Artin braid group on $n$ strings, $n \in N$, where $N$ denotes the set of natural numbers. R. Lawrence described in 1990 a family of so called Lawrence representations of $B_{n}$. Around 2001 S. Bigelow [11] and D. Krammer [12] independently proved that all braid groups $B_{n}$ are linear. Their work used new the Lawrence-Krammer representations $\rho_{n}: B_{n} \rightarrow \mathrm{GL}_{n(n-1) / 2}\left(Z\left[t^{ \pm 1}, s^{ \pm 1}\right]\right)$ that has been proved faithful for every $n \in N$. One can effectively find the image $\rho_{n}(g)$ for every element $g \in B_{n}$.

Moreover, there exists an effective procedure to recover a braid $g \in B_{n}$ from its image $\rho_{n}(g)$. It was shown in [13] that it can be done in $\mathrm{O}\left(m^{3} \log d_{t}\right)$ multiplications of entries in $\rho_{n}(g)$. Here $m=n(n-1) / 2$ and $d_{t}$ is a parameter that can be effectively computed by $\rho_{n}(g)$. See [13] for details.

\section{Complexity of the proposed cryptanalysis}

In this paper we proposed a polynomial time deterministic algorithm to recover secret; keys established by the protocols 1 and 2 in [3]. We assumed that the group $G$ in this protocols is linear. The authors of [3] suggested that the infinite nonabelian groups $B_{n}$ with $n \geq 12$ can be taken as the platform groups for the protocols 1 and 2 in [3]. By the Lawrence-Krammer representations the groups $B_{n}$ are linear. Moreover, this representations are effective computable and invertible. Unfortunately, in this setting the proposed protocols are not secure. Our cryptanalysis in the above sections shows that the linear decomposition attack works effectively in this case.

We present a cryptanalysis such that all used tools consist of only classical Gauss elimination process. It is well known that the Gauss elimination process is a polynomial procedure. To estimate the upper bound of the number of the field operations used by the algorithm, observe first that the number of the field operations in Gauss elimination performed on a matrix of size $n \times r$ is $\mathrm{O}\left(n^{2} r\right)$. Hence it requires at most $\mathrm{O}\left(n^{2} r\right)$ steps to construct $L_{0}$ from $W$, where $n=|W|$ is the number of elements in $W$. Notice that $\left|L_{j}\right| \leq r$ for every $j$. So to find $L_{j+1}$ it suffices to perform Gauss elimination on the matrix corresponding to $L_{j} \cup L_{j}^{U}$ which has size at most $r+r|U|$. Thus the upper estimate on this number is $\mathrm{O}\left(r^{3}|U|^{2}\right)$. Since there are at most $r$ iterations of this procedure one has the total estimate as $\mathrm{O}\left(r^{3}|U|^{2}+r|W|^{2}\right)$. When we derive solutions in (1)-(3) and in (7)-(9) we can estimate the time complexity by a polynomial function depending of the dimension $r$ of the space $V$ and the parameter $m=\max \{|A|,|B|\}$ as $\mathrm{O}\left(r^{3} m^{2}\right)$. With this estimation we can compute the secret keys in the form of matrices. If the platform $B_{n}$ is given by an abstract presentation, we can use the Lawrence-Krammer's representation, and then its inverse. It was shown in [14] that both these procedures are polynomial in time. Details can be found in [14].

Similar cryptanalysis can be applied to many other protocols based on (semi) groups presented as linear (semi)groups. Moreover, in a number of other cases we can firstly transform our platform to the linear form, and then apply our cryptanalysis. But in this latter case we should care about dimension of representation. Moreover, we need in tractable inverse map. All such topics open new area of pure theoretical investigations 
in the representation theory. Fortunately, studying of algebraic algorithms with a point of view of its possible practical application are led by many mathematicians. There are a lot of interesting and useful results in this direction.

Supported by Russian Foundation for Basic Research, project 15-41-04312.

\title{
References
}

1 Романьков В.А. Алгебраическая криптография. - Омск: ОмГУ, 2013. - С. 135.

2 Романьков В.А. Криптоанализ некоторых схем, использующих автоморфизмы // Прикладная дискретная математика. - 2013. - № 3. - С. 35-51.

3 Wang X., Xu C., Li G., Lin H., Wang W. Double shielded public key cryptosystems // Cryptology ePrint Archive Report 2014/588. - 2014. - P. 1-14.

4 Ko K.H., Lee S.J., Cheon J.H., Han J.W., Kang J., Park C. New public-key cryptosystem using braid groups // Advances in Cryptology. CRYPTO 2000. - Vol. 1880 (Lecture Notes Comp. Sc.) - Berlin: Springer, 2000. - P. 166-183.

5 Wang L., Wang L., Cao Z., Okamoto E., Shao J. New constructions of public-key encryption schemes from conjugacy search problems // Information security and cryptology. (Lecture Notes Comp. Sc.) Berlin: Springer, 2010. - Vol. 6584. - P. 1-17.

6 Stickel E. A New Method for Exchanging Secret Keys // Proc. of the Third Intern. Conf. on Information Technology and Applications (ICITA 05). Contemp. Math. (IEEE Computer Society). - 2005. - Vol. 2. - P. 426-430.

7 Alvarez R., Martinez F.-M., Vicent J.F., Zamora A. A Matricial Public Key Cryptosystem with Digital Signature // WSEAS Trans. on Math. - 2008. - Vol. 4(7). - P. 195-204.

8 Shpilrain $V$., Ushakov A.A new key exchange protocol based on the decomposition problem // Algebraic Methods in Cryptography Contemp. Math. - 2006. - Vol. 418. - P. 161-167.

9 Mahalanobis A. The Diffie-Hellman key exchange protocol and non-abelian nilpotent groups // Israel Math. Journal. - 2008 - Vol. 165. - P. 161-187.

10 Habeeb M., Kahrobaei D., Koupparis C., Shpilrain V. Public key exchange using semidirect product of (semi)groups. - [ER]. Access mode: arXiv math.: 1304.6572v1[cs.CR]. 24 Apr. 2013. - P. 1-12.

11 Марков В.Т., Михалев А.В., Грибов А.В., Золотых П.А., Скажсеник С.С. Квазигруппы и кольца в кодировании и построении криптосхем // Прикладная дискретная математика. - 2012. - № 4. C. $35-52$.

12 Bigelow S. Braid groups are linear // Amer. Math. Soc. Journal. - 2001. - Vol. 1. - P. 471-486.

13 Krammer D. Braid groups are linear // Ann. Math. - 2002. - Vol. 155. - P. 131-156.

14 Cheon J.H., Jun B. A Polynomial Time Algoritm for the Braid Diffie-Hellman Conjugacy Problem // Advances in Cryptology. CRYPTO-2003. Lect. Notes in Comput. Sci. - 2003. - Vol. 2729. - P. 212-225.

\section{B.А. Романьков}

\section{Өрімге негізделген ашық кілті бар қос панельдік шифрлау жүйесі үшін полиномиалды алгоритм}

\begin{abstract}
Мақалада ашық кілтпен кемерлер шифрлау жүйесінде негізделген криптографиялық талдау үшін алгоритм уақыты бойынша детерминдік полиномдық практикалық жаңа дәлелденетін Ванга, Ксу, Ли, Лин және Вана «Double shielded public key eryptosystems» ұсынылды. Автор платформа орнына $B_{n}$ Артина кемер группасын қолдануға кеңес берді. Осы жүмыста автордың жүргізген сызықтық декомпозициялық бағыты бөліктелген әдіске негізделген Лоуренс-Крамер түсінігіне қатысты кемер бейнесіне қолданылып көрсетілген. Нәтижесінде [3] хаттамаға негізделген қос бөлінген кілттер табылды. Бұл кілттер оларды айқын түрде де белсенді есептейді. Осылайша [3] хаттамада осалдығы орнатылған.
\end{abstract}




\title{
В.А. Романьков
}

\section{Полиномиальный алгоритм для основанной на косах системы шифрования с открытым ключом двойного щита}

\begin{abstract}
В статье предложен новый доказуемый практический детерминистский полиномиальный по времени алгоритм для криптографического анализа, основанный на косах системы шифрования с открытым ключом Ванга, Ксу, Ли, Лин и Ванга «Double shielded public key cryptosystems». Рекомендованы к использованию в качестве платформ группы кос Артина $B_{n}$. Показана, линейной декомпозиционной атаки, основанной на методе разложения, введенном автором, применимость к образам кос относительно представления Лоуренс-Крамера. В результате найдены разделенные ключи в обоих основных протоколах из [3]. Эти ключи эффективно вычисляются и в их оригинальном виде. Тем самым установлена уязвимость протоколов из [3].
\end{abstract}

\section{References}

1 Roman'kov V.A. Algebraic cryptography, Omsk: Omsk State University, 2013, p. 135.

2 Roman'kov V.A. Discrete Applied Mathematics, 2013, 3, p. 35-51.

3 Wang X., Xu C., Li G., Lin H., Wang W. Cryptology ePrint Archive Report 2014/588, 2014, p. 1-14.

4 Ko K.H., Lee S.J., Cheon J.H., Han J.W., Kang J., Park C. Advances in Cryptology. CRYPTO 2000. Vol. 1880 (Lecture Notes Comp. Sc.), Berlin: Springer, 2000, p. 166-183.

5 Wang L., Wang L., Cao Z., Okamoto E., Shao J. Information security and cryptology, (Lecture Notes Comp. Sc.), Berlin: Springer, 2010, 6584, p. 1-17.

6 Stickel E. Proc. of the Third Intern. Conf. on Information Technology and Applications (ICITA 05), Contemp. Math. (IEEE Computer Society), 2005, 2, p. 426-430.

7 Alvarez R., Martinez F.-M., Vicent J.F., Zamora A. WSEAS Trans. on Math., 2008, 4 (7), p. $195-204$.

8 Shpilrain V., Ushakov A. Algebraic Methods in Cryptography. Contemp. Math., 2006, 418, p. $161-167$.

9 Mahalanobis A. Israel Math. Journal, 2008, 165, p. 161-187.

10 Habeeb M., Kahrobaei D., Koupparis C., Shpilrain V. [ER]. Access mode: arXiv math.: 1304.6572v1 [cs.CR], 24 Apr. 2013, p. 1-12.

11 Markov V.T., Mihalyov A.V., Gribov A.V., Zolotyh P.A., Skazhenik S.S. Discrete Applied Mathematics, 2012, 4, p. 35-52.

12 Bigelow S. Amer. Math. Soc. Journal, 2001, 1, p. 471-486.

13 Krammer D. Ann. Math. Journal, 2002, 155, p. 131-156.

14 Cheon J.H., Jun B. Advances in Cryptology. CRYPTO-2003, Lect. Notes in Comput. Sci., 2003, 2729, p. $212-225$. 